\title{
Local geomagnetic field fluctuations relationship with mental and physical health among adults in Lithuania
}

\author{
Roza Joffè-Luinienè ${ }^{1}$, Alfonsas Vainoras ${ }^{2}$, Kastytis Šmigelskas ${ }^{3}$ \\ Lithuanian University of Health Sciences, Health Research Institute, Kaunas, Lithuania \\ ${ }^{1}$ Corresponding author \\ E-mail: ${ }^{1}$ joffero@gmail.com, ${ }^{2}$ alfavain@gmail.com, ${ }^{3}$ kastsmig@gmail.com \\ Received 7 May 2019; received in revised form 4 June 2019; accepted 12 June 2019 \\ DOI https://doi.org/10.21595/chs.2019.20855
}

Check for updates

Copyright (C) 2019 Roza Joffe-Luiniene, et al. This is an open access article distributed under the Creative Commons Attribution License, which permits unrestricted use, distribution, and reproduction in any medium, provided the original work is properly cited.

\begin{abstract}
The study examined the relationship between local geomagnetic field fluctuations and physical and mental health among young adults in Lithuania. 264 participants were recruited for a two-week period study, during which they had to fill-in paper questionnaires, consisting of a 12-Item Short Form Survey (SF-12), assessing physical and mental health, 4 questions about physical vitality, emotional vitality, social wellbeing and overall wellbeing, and questions regarding sociodemographic data. The results of the study revealed that possible influence of geomagnetic field fluctuations appear not simultaneously with the changes in human health status, but with a 12-hour lag. This relationship was found to be weak but significant, however, only with mental health.
\end{abstract}

Keywords: geomagnetic field, mental health, physical health.

\section{Introduction}

Invisible fluctuating magnetic fields inevitably reach all human beings on the Earth, as being a part of a biological system [1]. Scientists have well described that geomagnetic field resonances generate a range of resonant frequencies that are directly linked to the physiological processes in human brain, autonomic nervous system (ANS), and cardiovascular system. It is also proposed that every living organism on the Earth has a specific and unique sensitivity to the strength and frequency of geomagnetic field fluctuations $[2,3]$.

Recent studies proved that both - weak and strong - geomagnetic field disturbances are associated with negative health outcomes $[4,5]$. It is commonly recognized, that geophysical environment factors may stimulate social unrest by influencing the mental state of people [6]. Increased rates of violence, crime, revolutions, frequency of terrorist attacks also have been significantly linked to geomagnetic activity factors [7-9]. A number of studies have demonstrated evidence that geomagnetic and solar influences affect human behavioral and health outcomes, the nervous and cardiovascular systems being the most clearly impacted [10-12].

Doronin et al. [13] in their study that compared low-frequency geomagnetic rhythms with electroencephalogram (EEG) rhythms, blood pressure, heart rate, and reaction times, revealed that the variations in both heart and brain patterns were associated with changes in geomagnetic activity simultaneously. Stoupel et al. [14] have found significant links between geomagnetic activity, accompanied by high Cosmic Ray Activity (neutron activity), and rises in more medical emergencies and total daily death number. In another study performed by this researcher [15], low GMA was associated with more sudden deaths, some increase in electrical heart instability number of ventricular and supraventricular extrasystoles and higher rate of ventricular tachycardia.

From what has been discussed, it becomes obvious that quite a large number of psychophysiological rhythms are affected by and can synchronize with solar and geomagnetic activity $[9,11,13,16]$. However, most of the introduced researches reflect objective health parameters, which produces a lack of studies that would assess subjectively perceived data on physical, mental wellbeing and its relationship with geomagnetic activity. Subjectively perceived wellbeing of a person is an important and significant indicator for analyzing and predicting his/her 
immediate future health changes and healthcare needs [17]. A person's subjective assessment of his/her health status and overall wellbeing is most often determined by biomedical, functional and emotional components $[17,18]$. A number of scientists $[17,19,20]$ emphasize that it is the subjective rather than the objective assessment of health status and wellbeing that is a particularly important and significant prognostic indicator, therefore, it was decided in this study to rely on subjectively assessed health and wellbeing of the subjects.

\section{Methods and procedures}

\subsection{Participants}

The study took place in Kaunas, Lithuania. Healthy young adults (19-39 age) were recruited for the study. The study for each participant lasted two weeks in a row, therefore, in order to recruit a sufficient number of participants who would agree to stay in the study for this period, participants were recruited in groups. Starting in March, 2016, until the end of October, 2016, 5 runs of two-week study periods were organized. A total of 264 participants data were included into the final analysis. The mean age (sd) of the 264 participants in the analysis was $26(6,37)$ years consisting of 184 females and 79 males.

\subsection{Ethics statement}

The performed study was in compliance with the ethics of experimentation in accordance with the Declaration of Helsinki. The permit to perform biomedical research was granted by the Kaunas Regional Ethics Committee for Biomedical Investigations, No. BE-2-51, 23.12.2015 (copies of documents are enclosed as supplemental data). Each participant signed a paper consent prior to the study.

\subsection{Health parameters data collection}

Participants had to fill in paper questionnaires, consisting of 12-Item Short Form Survey (SF-12), 4 questions about physical vitality, emotional vitality, social wellbeing and overall wellbeing, and questions regarding sociodemographic data.

SF-12 has been extensively used as a valid measure of self-reported health-related quality of life in a variety of population groups [21], including adults' population in Kaunas city [22]. The questionnaire consists of twelve questions that measure eight health domains to assess physical and mental health. Physical health-related domains include General Health, Physical Functioning, Role Physical, and Body Pain. Mental health-related scales include Vitality, Social Functioning, Role Emotional, and Mental Health.

4 questions about physical vitality, emotional vitality, social wellbeing and overall wellbeing were constructed consulting the HeartMath Institute Research Director Rollin McCraty. The questions asked the participants to provide their responses by using a 5-point Likert scale.

\subsection{Magnetic field data}

The local magnetic field fluctuations data was gathered using a magnetometer located in Lithuania. The device is a part of the Global Coherence Monitoring Network [1]. Two magnetic field detectors (Zonge Engineering ANT-4) at the site are positioned in the north-south and east-west axes to detect local time-varying magnetic field strengths (sensitivity $1 \mathrm{pT}$ ) over a wide frequency range $(0.01-65 \mathrm{~Hz})$ while maintaining a flat frequency response. The mechanism of the data acquisition captures, then stamps the global positioning system time, and transmits the data to the common server. 


\subsection{Identification of correlations between health parameters and geomagnetic field fluctuations}

For identification of correlations between mental, physical health parameters and geomagnetic field fluctuations, Spearman's correlation coefficient was applied. For the analysis, the Statistical Package for the Social Sciences (SPSS), 20 version was used.

\section{Results}

The results of the analysis of correlations between geomagnetic field fluctuations, mental and physical health are presented in Table 1 and Table 2. Geomagnetic field is ranged in 6 different frequency ranges. Table 1 reflects the relationships at the same time, whereas Table 2 shows the relationships with a 12-hour lag (geomagnetic field fluctuations that occurred 12 hours prior the participants' health parameters were assessed).

Table 1. Geomagnetic field fluctuations relationship with physical and mental health

\begin{tabular}{|c|c|c|c|c|c|c|c|}
\hline & & $\begin{array}{c}\text { Frequency } \\
0-3,5 \mathrm{~Hz}\end{array}$ & $\begin{array}{c}\text { Frequency } \\
3,5-7 \mathrm{~Hz}\end{array}$ & $\begin{array}{c}\text { Frequency } \\
7-15 \mathrm{~Hz}\end{array}$ & $\begin{array}{c}\text { Frequency } \\
15-32 \mathrm{~Hz}\end{array}$ & $\begin{array}{c}\text { Frequency } \\
32-65 \mathrm{~Hz}\end{array}$ & $\begin{array}{c}\text { Frequency } \\
0-65 \mathrm{~Hz}\end{array}$ \\
\hline \multirow{3}{*}{ SF physical } & $R$ & 0,029 & 0,036 & 0,042 & 0,050 & 0,017 & 0,040 \\
\hline & $p$ & $>0,001$ & $>0,001$ & $>0,001$ & $>0,001$ & $>0,001$ & $>0,001$ \\
\hline & $N$ & 3420 & 3420 & 3420 & 3420 & 3420 & 3420 \\
\hline \multirow{3}{*}{$\begin{array}{c}\text { SF mental } \\
\text { Physical vitality }\end{array}$} & $R$ & 0,048 & 0,027 & 0,001 & 0,004 & 0,029 & 0,027 \\
\hline & $p$ & $>0,001$ & $>0,001$ & $>0,001$ & $>0,001$ & $>0,001$ & $>0,001$ \\
\hline & $N$ & 3420 & 3420 & 3420 & 3420 & 3420 & 3420 \\
\hline \multirow{3}{*}{ SF physical } & $R$ & 0,040 & 0,039 & 0,020 & 0,015 & $-0,005$ & 0,014 \\
\hline & $p$ & $>0,001$ & $>0,001$ & $>0,001$ & $>0,001$ & $>0,001$ & $>0,001$ \\
\hline & $N$ & 3449 & 3449 & 3449 & 3449 & 3449 & 3449 \\
\hline \multirow{3}{*}{ SF mental } & $R$ & 0,029 & 0,027 & 0,015 & 0,008 & 0,000 & 0,010 \\
\hline & $p$ & $>0,001$ & $>0,001$ & $>0,001$ & $>0,001$ & $>0,001$ & $>0,001$ \\
\hline & $N$ & 3448 & 3448 & 3448 & 3448 & 3448 & 3448 \\
\hline
\end{tabular}

Table 2. Geomagnetic field fluctuations relationship with physical and mental health with a 12-hour lag

\begin{tabular}{|c|c|c|c|c|c|c|c|}
\hline \multicolumn{2}{|c|}{} & $\begin{array}{c}\text { Frequency } \\
0-3,5 \mathrm{~Hz}\end{array}$ & $\begin{array}{c}\text { Frequency } \\
3,5-7 \mathrm{~Hz}\end{array}$ & $\begin{array}{c}\text { Frequency } \\
7-15 \mathrm{~Hz}\end{array}$ & $\begin{array}{c}\text { Frequency } \\
15-32 \mathrm{~Hz}\end{array}$ & $\begin{array}{c}\text { Frequency } \\
32-65 \mathrm{~Hz}\end{array}$ & $\begin{array}{c}\text { Frequency } \\
0-65 \mathrm{~Hz}\end{array}$ \\
\hline \multirow{3}{*}{ SF physical } & $R$ & 0,008 & 0,012 & 0,000 & $-0,022$ & $-0,011$ & $-0,012$ \\
\cline { 2 - 8 } & $p$ & $>0,001$ & $>0,001$ & $>0,001$ & $>0,001$ & $>0,001$ & $>0,001$ \\
\cline { 2 - 8 } & $N$ & 3420 & 3420 & 3420 & 3420 & 3420 & 3420 \\
\hline \multirow{3}{*}{$\begin{array}{c}\text { SF mental } \\
\text { Physical vitality }\end{array}$} & $R$ & 0,102 & 0,110 & 0,119 & 0,065 & $-0,026$ & 0,026 \\
\cline { 2 - 8 } & $p$ & $<0,001$ & $<0,001$ & $<0,001$ & $<0,001$ & $>0,001$ & $>0,001$ \\
\cline { 2 - 8 } SF physical & $N$ & 3420 & 3420 & 3420 & 3420 & 3420 & 3420 \\
\cline { 2 - 8 } & $R$ & 0,034 & 0,035 & 0,035 & $-0,003$ & $-0,033$ & $-0,018$ \\
\cline { 2 - 8 } & $N$ & 3449 & 3449 & 3449 & 3449 & 3449 & 3449 \\
\hline \multirow{3}{*}{ SF mental } & $R$ & 0,042 & 0,052 & 0,064 & 0,034 & $-0,008$ & 0,012 \\
\cline { 2 - 8 } & $p$ & $>0,001$ & $>0,001$ & $<0,001$ & $>0,001$ & $>0,001$ & $>0,001$ \\
\cline { 2 - 8 } & $N$ & 3448 & 3448 & 3448 & 3448 & 3448 & 3448 \\
\hline$R$
\end{tabular}

As it can be seen from Table 1, that there were no significant relationships found between geomagnetic field fluctuations and health parameters when estimating at the same time of occurrence.

From the data in Table 2, it can be seen that weak correlations appear in four different frequency ranges when estimating mental health and geomagnetic field fluctuations with a 
12-hour lag.

\section{Limitations of the study}

Our study has some limitations. First, we included only subjectively assessed data about the participants' health parameters. Due to a study period of two weeks, this may have resulted in a loss of motivation to provide sincere answers regarding the participants' everyday health status, which, in turn, may have influenced inaccurate results of the study. Objective measures of health parameters would have contributed to more accurate results. Further studies including not only subjective, but also objective measures of health parameters, or/and shortening the study period in order to maintain the participants motivation, are necessary.

\section{Conclusions}

The discussed study examined geomagnetic field fluctuations relationship with mental and physical health among young adults in Lithuania. The results of the conducted study suggest that possible influence of geomagnetic field fluctuations appear not simultaneously with the changes in human health status, but with a 12-hour lag. This relationship was found to be weak but significant, however, only with mental health. Results of the study propose that perhaps not only subjective, but also objective assessment of current health parameters might be of great value in order to obtain better and more accurate data. A more complex design of the study, including objective data about participants' health parameters, is an object for future analysis.

\section{Acknowledgements}

In 2014, HeartMath Institute (California, USA) financed and coordinated the installation of two magnetic field detectors (Zonge Engineering ANT-4) that measure a local time-varying magnetic field strengths (sensitivity $1 \mathrm{pT}$ ) over a wide frequency range $(0.01-65 \mathrm{~Hz})$ in Lithuania. Thanks to this huge investment, we have been able to start researching relationships between various health related phenomena and local geomagnetic field fluctuations in Lithuania.

\section{References}

[1] McCraty R., Deyhle A. Bioelectromagnetic and Subtle Energy Medicine. Second Edition, CRC Press, 2015.

[2] Alabdulgader A., McCraty R., Atkinson M., Vainoras A., Berškienė K., Mauricienė V., Daunoravičienė A., Navickas Z., Šmidtaitė R., Landauskas M. Human heart rhythm sensitivity to earth local magnetic field fluctuations. Journal of Vibroengineering, Vol. 17, 2015, p. 3271-3278.

[3] Liboff A. R. A role for the geomagnetic field in cell regulation. Electromagnetic Biology and Medicine, Vol. 29, 2010, p. 105-112.

[4] Hardell L. World Health Organisation, radiofrequency radiation and health - a hard nut to crack (Review). International Journal of Oncology, Vol. 51, 2017, p. 405-413.

[5] Huss A., Peters S., Vermeulen R. Occupational exposure to extremely low-frequency magnetic fields and the risk of ALS: A systematic review and meta-analysis. Bioelectromagnetics, Vol. 39, 2018, p. $156-163$.

[6] Tchijevsky A. L. Physical factors of the historical process. Cycles, Vol. 22, 1971, p. 11-27.

[7] Mikuleckỳ M. Solar activity, revolutions and cultural prime in the history of mankind. Neuroendocrinology Letters, Vol. 28, 2007, p. 749-756.

[8] Smelyakov S. V. Tchijevsky's Disclosure: How the Solar Cycles Modulate the History, 2006.

[9] Halberg F., Cornelissen G., McCraty R., Al-Abdulgader A. Time structures (chronomes) of the blood circulation, populations' health, human affairs and space weather. World Heart Journal, Vol. 3, 2001, p. 1-40.

[10] McCraty R., Atkinson M., Stolc V., Alabdulgader A. A, Vainoras A., Ragulskis M. Synchronization of human autonomic nervous system rhythms with geomagnetic activity in human 
subjects. International Journal of Environmental Research and Public Health, Vol. 14, Issue 7, 2017, p. E770.

[11] Khorseva N. Using psychophysiological indices to estimate the effect of cosmophysical factors (Review). Izvestiya, Atmospheric and Oceanic Physics, Vol. 49, 2013, p. 839-852.

[12] Freund F., Stolc V. Nature of pre-earthquake phenomena and their effects on living organisms. Animals, Vol. 3, 2013, p. 513-531.

[13] Doronin V. N., Parfentev V. A., Tleulin Zh. S., Namvar R. A., Somsikov V. M., Drobzhev V. I., Chemeris A. V. Effect of variations of the geomagnetic field and solar activity on human physiological indicators. Biofizika, Vol. 43, 1998, p. 647-653.

[14] Stoupel E., Babayev E. S., Abramson E., Sulkes J. Days of "Zero" level geomagnetic activity accompanied by the high neutron activity and dynamics of some medical events - Antipodes to geomagnetic storms. Health, Vol. 5, 2013, p. 855-861.

[15] Stoupel E. The effect of geomagnetic activity on cardiovascular parameters. Biomedicine and Pharmacotherapy, Vol. 56, 2002, p. 247-256.

[16] Khabarova O., Dimitrova S. On the nature of people's reaction to space weather and meteorological weather changes. Sun and Geosphere, Vol. 4, 2009, p. 60-71.

[17] Saevareid H. I., Thygesen E., Nygaard H. A., Lindstrom T. C. Does sense of coherence affect the relationship between self-rated health and health status in a sample of community-dwelling frail elderly people? Aging and Mental Health, Vol. 11, 2007, p. 658-667.

[18] Kaplan G., Baron-Epel O. What lies behind the subjective evaluation of health status? Social Science and Medicine, Vol. 56, Issue 8, 2003, p. 1669-1676.

[19] Menec V. H., Chipperfield J. G. A prospective analysis of the relation between self-rated health and health care use among elderly Canadians. Canadian Journal on Aging, Vol. 20, Issue 3, 2001, p. 293-306.

[20] Idler E. L, Russel L. B, Davis D. Survival, functional limitations, and self-rated health in the NHANES I Epidemiologic Follow-up Study, 1992. First National Health and Nutrition Examination Survey. American Journal of Epidemiology, Vol. 152, Issue 9, 2000, p. 874-83.

[21] Huo T., Guo Y., Shenkman E., Muller K. Assessing the reliability of the short form 12 (SF-12) health survey in adults with mental health conditions: a report from the wellness incentive and navigation (WIN) study. Health and Quality of Life Outcomes, Vol. 16, 2018, p. 34.

[22] Krančiukaitė D., Rastenytė D., Jurẻnienė K. Kauno populiacijos gyvenimo kokybės vertinimas naudojant SF-12 klausimyną. Medicina (Kaunas), Vol. 43, Issue 6, 2007, p. 501-507. 